\title{
EX-AEQUO: CONTRIBUTO DECISIVO PARA UM CAMPO DE ESTUDOS EM PORTUGAL
}

\author{
TERESA JOAQUIM \\ Centro de Estudos das Migrações e das Relações Interculturais Universidade \\ Aberta
}

Resumo: Apresentação da revista Ex-Æqquo (da Associação Portuguesa de Estudos sobre as Mulheres), no ambito da institucionalização dos estudos sobre as mulheres e sobre gênero em Portugal e no contexto de uma sociedade democrática.

Palavras-chove: estudos sobre as mulheres; género; igualdade; feminismo; Portugal.

\begin{abstract}
Bem sei que a revolta das mulheres é que leva à convulsão em todos os extractos sociais: nada fica de pé, nem relações de classe, nem de grupo, nem individuais, toda a repressão terá de ser desenraizada [...]. Tudo terá de ser novo. [...] E o problema da mulher no meio disto, não é o de perder ou ganhar, é o da identidade (As Novas Cartas Portuguesas, 1972, p. 231).
\end{abstract}

A revista EX-ÆEQUO é uma publicação de cariz científica, editada pela Associação Portuguesa de Estudos sobre as Mulheres (APEM) e publicada pela Celta Editora. Esta Associação, 1 criada em 1991 e contando 216 sócios em 2001, 8 dos quais do sexo masculino, constituída sobretudo, mas não exclusivamente, por investigadoras nas áreas das ciências sociais, predominantemente nas áreas de História, Serviço Social, Psicologia Social, Ciências da Educação, Sociologia e poucas de Antropologia, surgiu na seqüência de um trabalho que tem vindo a ser realizado, nomeadamente a partir da Revolução de 1974,2 e que pretende constituir uma área de estudos. Tarefa essa que não tem sido fácil nem linear e que, na minha opinião, tem tido sempre um cariz problemático e marginal no contexto científico da área portuguesa das ciências sociais, lembrando o que Hegel dizia de Antígona, como a "eterna ironia da comunidade". E passamos a explicar o que pode significar essa ironia.

A área de estudos a que nos referimos é a dos Estudos sobre as Mulheres, denominação que incide, entre outros, sobre dois aspectos, a saber: o contexto e a evolução das Ciências Sociais em Portugal, por um lado e a sua possível articulação com o movimento feminista, por outro. Seria necessário reflectir sobre a história da investigação científica social em Portugal, as suas omissões e aberturas aos 'novos' objectos como juventude, quotidiano, corpo, família, e também as 'mulheres'. O outro aspecto é saber se houve (ou se há) alguma articulação entre o movimento feminista e o aparecimento 
de cursos, seminários, mestrados, etc. ao nível das instituições universitárias (criação do $1^{\circ}$ Mestrado em Estudos sobre as Mulheres, em 1995, na Universidade Aberta, universidade pública em Lisboa).

Se partirmos desta afirmação de Rosi Braidotti, "os estudos feministas representam uma tentativa das mulheres em reunirem teoria, trabalho intelectual e prática política tendo em vista a melhoria do seu estatuto social e simbólico"3.

Esta questão deveria ainda ser articulada com a afirmação de posições diferentes sobre a existência ou não de um movimento feminista no pós 25 de Abril de 1974 e a sua possível incidência nos Estudos sobre as Mulheres a fim de situarmo-nos hoje 30 anos após o 25 de Abril, esse acontecimento, esses "dias levantados", no belo título de Manuel Gusmão que, segundo ele, "porque foi um processo de transformação do nosso espaçotempo e das nossas maneiras de habitar e porque foi um processo de irrupção de imensas vozes e corpos no teatro da história tal como a fazemos",4 porque os feminismos surgem da mesma linha original, do mesmo desejo que os funda - essa "irrupção de vozes" - de criação de vozes, diversas, plurais, polifónicas.

Porque os feminismos e os estudos sobre as mulheres são certamente também formas diversas de poder habitar a teoria e as práticas de outro modo. De reler as experiências múltiplas das mulheres, algumas na sua insignificância, dando-Ihes sentido e daí possibilidades de vida, de serem passíveis de serem transmitidas como herança às gerações vindouras, herança feita da passagem do testemunho entre as feministas da geração do início do século passado e as mulheres que se afirmaram pós 25 de Abril de 1974, ou ainda ausência de transmissão entre as mulheres da oposição ao Estado Novo e as do pós 25 de Abril.

A própria denominação Estudos sobre as Mulheres faz parte de um percurso histórico que deve ser integrado no contexto do desenvolvimento das Ciências Sociais e do feminismo em Portugal. Estudos sobre as Mulheres em que se inscreve este trabalho de "aparição de sujeitos sobre uma cena de comunidade" 5 , feito de modo diverso nas diferentes áreas dessas Ciências Sociais.

A categoria analítica de género tornou-se mais presente em Portugal nos anos 90 tendo como nó fulcral os aspectos relacionais da construção social do feminino (e do masculino). Tornou-se numa palavra passe-partout, nomeadamente na sua emigração e tradução em contextos institucionais cuja utilização - nessa tradução institucionalizada é muitas vezes indevida, por escamotear a crítica que essa categoria analítica implícita, podendo-se fazê-la 'despolitizar' a luta das mulheres.

Categoria analítica que se tornou um contributo teórico importante, mas que não é reconhecido na sua fonte, que é 'cortada' da área dos estudos sobre as mulheres, das teorias feministas, havendo neste caso a despolitização também do conceito. O que Colette Guillaumin, no texto "Mulheres e teorias de sociedade. Notas sobre os efeitos teóricos da cólera das oprimidas", refere-se deste modo:

Aquilo a que podemos chamar 'teorias da sociedade' no sentido em que as compreendemos hoje, foram todas - e são - a forma intelectual de relações sociais determinadas. [...] A entrada das/os minoritárias/os no domínio teórico não conduz a falar propriamente de um 'afinamento' ou a uma 'diversificação' dos conhecimentos. Isso, certamente, pode produzir-se, mas o essencial não está aí, está na perturbação das perspectivas, na subversão que introduzem. Além de que, notemos isto, os primeiros textos teóricos vindos de grupos minoritários são sempre, na sua aparência e sem excepção, desqualificados no plano teórico e apresentados como produtos 'políticos'6.

... Estes textos minoritários, cuja publicação não é fácil [...] mas depois não se podem mais colocar os problemas da mesma maneira que anteriormente7. 
E, no entanto, se os problemas já não podem ser colocados da mesma maneira, não deve deixar de ser pensado o modo como estas categorias, por um lado são desapossadas desse mesmo contexto 'político', enquanto criadores e provocadores de novas formas de habitar no que isso implica como pensamento e saber, e por outro lado, estes estudos em Portugal continuam a ser maioritariamente realizados por investigadoras, dizendo-se implicitamente, não só a hierarquia de prestígio entre os sexos no mundo científico, como também entre os próprios objectos científicos.

Os Estudos sobre as Mulheres inscrevem-se pois, num movimento mais amplo de desconstrução que é inerente ao próprio exercício do pensamento na sua tarefa de sempre, de crítica e criação de novos conceitos.

A APEM tendo sido criada em 1991, a revista iniciou a sua publicação em 1997. Bianual, a sua tiragem ronda os 600 exemplares, sendo enviada às sócias da Associação e distribuída nas livrarias.

Desde 1977, foram editados os seguintes números:

1- Filosofia no feminino;

2-3 - Políticas para a Igualdade (comunicações de um colóquio da Associação); 4 - Mulheres e desporto;

5 e 6 - Balanço de 10 anos de actividade da APEM (2 volumes, com dossiês por áreas: filosofia, literatura, cultura, teatro, educação, psicologia social, direito, economia, sociologia e história);

7 - Novos sentidos para novas cidadanias;

8 - Reconceptualizações filosóficas e de teoria política - Perspectivas feministas (colectânea de textos de teóricas feministas), sendo o n. 9 próximo sobre literatura e filosofia.

Todos estes números, com excepção do n. 8, claro, resultaram de comunicações e colóquios da revista EX-AEQUO.

O título da revista refere a expressão usada num concurso para traduzir a situação de igualdade de desempenho em igualdade de circunstâncias. Na minha opinião, ele reflecte de certo modo como a própria constituição deste campo de Estudos sobre as Mulheres esteve, após 1974, ligado a uma instituição da Administração Pública para a igualdade, a Comissão da Condição Feminina (1977), posteriormente Comissão para a Igualdade e para os Direitos das Mulheres. Podemos tentar esboçar a periodização da sua implementação, os momentos que vão constituindo uma problemática sobre a "condição feminina", como então se chamava.

1. Um primeiro momento antes do 25 de Abril com a criação de comissões (Grupo de Trabalho para a Participação da Mulher na Vida Económica, 1970, Comissão para a Política Social relativa à Mulher, 1973), o aparecimento de encontros como o da Faculdade de Direito em 1968 - Colóquio sobre a Condição da Mulher Portuguesa - e, sobretudo, a publicação das Novas Cartas Portuguesas em 1972, afirmação radical sobre diversos modos de ser e estar, também a sua marginalidade.

2. Após 74 , a criação da CCF, como anteriormente referi, que marcou "um feminismo institucional", com a criação de um Centro de Documentação, seminários, contactos com a comunidade científica, constituição de um fundo documental de textos históricos do feminismo do passado em português, etc.

3. $\bigcirc 3^{\circ}$ momento foi marcado pela constituição de Associações como a APEM (1991) e a APHIM (Associação Portuguesa de História e Investigação sobre as Mulheres, 1997) e pela publicação de revistas como a Ex-AEquo e as Faces de Eva. Pela institucionalização, ao nível do ensino superior, do Mestrado em Estudos sobre as Mulheres (1995), na Universidade Aberta. A que se seguiu o aparecimento de disciplinas e outros 
cursos e opções, linhas de investigação em Centros de investigação, etc. Movimento que irá certamente continuar na sua disseminação em cursos que irão ser implementados em outras Faculdades; penso que, no futuro, este é um movimento que deverá ser avaliado, a saber, as formas de organização dos cursos (as disciplinas convocadas ou excluídas, as temáticas abordadas).

Outro aspecto fundamental é a produção de dissertações e a sua divulgação. Importante seria não só a análise dos objectos de estudo abordados como também o nível de aprofundamento teórico dos mesmos, na sua inovação ou na sua repetição.

Voltando um pouco atrás e ao modo como se foi constituindo este campo de estudos ligado a mecanismos para a igualdade o que, como refere Virgínia Ferreira, então presidente da APEM, na apresentação da revista no seu n. 1, reflecte:

a) a falta de autonomia das ONG;

b) a débil mobilização da sociedade civil.

Segundo algumas investigadoras, isto é a marca de um feminismo institucional, caracterizado pela sua inserção no âmbito da democratização da sociedade portuguesa e das questões da igualdade. Portugal é hoje um país semi-periférico que em 30 anos teve que mudar da idéia (em grande parte) fantasmática de um império colonial para se resituar na Europa - um país que é o Sul do Norte - e reencontrar um espaço. Esta mudança rápida de dimensão e de relação com espaços diversos (reais e fantasmáticos) diz ela própria a situação também face ao movimento feminista no contexto europeu, face às mudanças internas no contexto pós 25 de Abril de 1974, face às diversas tradições teóricas que nos dão também a possibilidade de poder "navegar" em diversos contextos teóricos, sem escolhas, de sermos também por vezes, nesses contextos, um estudo de caso; sem podermos por vezes questionar os modelos teóricos dominantes, nomeadamente na forma de implementação desta área de estudos.

A EX-ÆQUO tem como objectivos:

1. O desenvolvimento, visibilização e legitimação científica da área científica Estudos sobre as Mulheres;

2. A promoção do intercâmbio entre investigadoras/es;

3. A contribuição para os debates das principais questões que afectam a sociedade portuguesa.

Pretende ser interdisciplinar e congregar a pulverização de núcleos de estudo não organizados. A sua edição seria rotativa, por pessoas ou associações inseridas nas várias estruturas de ensino e de investigação. Define-se como feminista, designação que é formulada numa pluralidade de perspectivas e ainda tendo como pretensão "o desafio à hegemonia intelectual masculina" (n. 1, p. 5, 1999).

Os números 5 e 6, sobre a estruturação dos Estudos sobre as Mulheres em Portugal, são muito interessantes e com a sua realização pretende-se:

1. um balanço / reflexão em torno das transformações induzidas pelos estudos sobre as Mulheres, tanto no campo teórico como nas práticas metodológicas;

2. a realização de levantamentos bibliográficos especializados;

3. e ainda o estudo sobre a própria evolução da Associação (APEM) e o cruzamento entre o percurso realizado, as expectativas que havia e o futuro. (cf. "Dez anos de APEM. Percorrer as vozes, significar os percursos", de $\mathrm{M}^{a}$ José Magalhães).

Neste texto é referido que para a maioria das sócias/investigadoras, a criação da Ex-AEquo marca a inserção da Associação na comunidade científica.

Nestes números foram analisadas as áreas seguintes: filosofia, literatura, cultura, teatro, educação, psicologia social, direito, economia, sociologia e história, tendo Virgínia Ferreira, de novo, referido a existência de duas estratégias em simultâneo: 
a) investir e desenvolver os estudos sobre as mulheres;

b) intensificar o diálogo transformador com as disciplinas institucionalizadas (n. 5 , p. 20); e ainda:

O discurso das autoras que aceitaram este desafio, para nosso regozijo e proveito, inscrevese no fio da navalha que separa o seu próprio campo disciplinar e o que estão a construir - o dos estudos sobre as mulheres. É também por isso que estes textos são tão ricos e constituem matéria de leitura tão interessante. A APEM espera com este projecto ter dado um contributo para a intensificação da cooperação no âmbito dos estudos sobre as mulheres, para a promoção da intertextualidade entre intelectuais que partilham muitas das problemáticas que ocupam a sua reflexão, ainda que a partir de áreas disciplinares diferentes, para o reforço da memória e para a visibilização para o círculo exterior de um novo campo científico em construção8.

Pelo que anteriormente referi, esta área de estudos e a existência da revista científica Ex-AEquo podem, em diálogo com outras áreas também elas ainda emergentes, constituir um desafio para as áreas disciplinares e científicas constituídas, pela inovação dos temas e das abordagens, pelo risco de transgressão das fronteiras disciplinares, pelos novos estilos de escrita, pela própria emergência e articulação com outros pontos de partida. Um deles pode ser, neste contexto, a discussão e o diferendo entre textos publicados de um e do outro lado do Atlântico, sabermos que temos "um oceano para nadar", como dizia o fítulo de uma exposição, ou para "navegar", entendido na sua polissemia.

\section{Notas}

Copyright (C) 2004 by Revista Estudos Feministas

1 www.apem.web.pt

2 "O 25 de abril é um dia e são dias, meses, anos. É daquelas datas que se constelam, que estão antes de hoje, que hoje ecoam ainda, e que tremeluzirão no depois de hoje como a memória de uma outra possibilidade no conflito dos possíveis reais. Porque foi um processo de irrupção de imensas vozes e corpos no teatro da história tal como a fazemos. Porque foi um processo de transformação do nosso espaço-tempo e das nossas maneiras de habitar. Porque foi a liberdade e a democracia como emancipação. Porque fol a política como poiesis. E por aí, através do som e da fúria da vida histórica, passa um sentido que julgamos vislumbrar, um sentido possível para a frase "rico em méritos, é contudo poeticamente que o homem habita sobre esta terra", que vem em Holderlin" (M. Gusmão, Os Dias Levantados, 2002, p. 98.)

3 Rosi BRAIDOTTI, 1990, p. 30.

4 Manuel GUSMÃO, 2002, p. 98

5 Jacques RANCIÈRE, 1997.

6 Colette GUILLAUMIN, 1981, p. 223

7 GUILLAUMIN, 1981, p. 224-5.

8 Virgínia FERREIRA, 1999, p. 10.

\section{Referências}

BARRENO, Maria Isabel; HORTA, Maria Teresa; VELHO DA COSTA, Maria. As Novas Cartas Portuguesas. Lisboa, Estúdios Cor, 1972.

BRAIDOTTI, Rosi. "Théories des études féministes: quelques expériences contemporaines en Europe". Les Cahiers du Grif, n. 45, p. 29-50. Paris: Tierce, 1990.

FERREIRA, Virgínia. "Editorial. Apresentação". Ex-cequo, n. 1, Oeiras, Ed. Celta, pp. 5-10, 1999.

FERREIRA, Virgínia. "Estudos sobre as Mulheres em Portugal: a construção de um novo campo científico. Ex-cequo, n. 6, Oeiras, Ed. Celta, pp. 9-25, 2002.

GUILLAUMIN,Colette. " Femmes et théories de sociéte. Notes sur les effets théoriques de la colère des oprimées ». In : GUILLAUMIN, Colette. Sexe, Race et Pratique de Pouvoir, I' idée de Nature. Paris: Côté- Femmes, 1992. 
GUSMÃO, Manuel. Os Dias Levantados. Caminho, Lisboa, 2002.

JOAQUIM, Teresa. "Os Estudos sobre as Mulheres em Filosofia". Ex-cequo, n. 5, Oeiras, Ed. Celta, pp. 69-106, 2001.

MAGALHÃES, Maria José. "Dez anos da APEM: percorrer as vozes, significar os discursos". Ex-cequo, n० 5, Oeiras, Ed. Celta, pp. 27-68, 2001.

RANCIÈRE, Jacques. "L'inoubliable". In: COMOLLI, Jean-Louis e RANCIÈRE, Jacques. Arrêt sur Histoire. Paris, Ed. Centre Georges Pompidou, 1997.

\section{EX-AEQUO: A Decisive Contribution to a Field of Studies}

Abstract: Presentation of the Ex-Aquu review (published by the Portuguese Association of Women s Studies), having in mind the institucionalization of women's studies and gender studies in Portugal in the context of a democratic society.

Keywords: women's studies; gender; equality; feminism; Portugal. 